\title{
Trends and inequities in beta-blocker prescribing for heart failure
}

\author{
Sunil M Shah, Iain M Carey, Stephen DeWilde, Nicky Richards and Derek G Cook
}

\begin{abstract}
Background

Treatment with specific beta-blockers reduces mortality and hospitalisation in heart failure.

Aim

To describe trends and inequities in beta-blocker prescribing for heart failure.

\section{Design of study}

Repeated cross-sectional analysis of a nationally representative primary care database (DIN-LINK).

Setting

A total of 152 UK general practices.

Method

Prescribing of beta-blockers between 2000 and 2005 was examined among a yearly average of 7294 patients aged $\geq 50$ years who had actively managed heart failure - defined as a recorded diagnosis of heart failure and two prescriptions of an angiotensinconverting enzyme inhibitor or angiotensin receptor blocker during the calendar year. The main outcome was the prescription of a guideline-recommended beta-blocker (bisoprolol, carvedilol, metoprolol, or nebivolol) in the year. Determinants of beta-blocker prescribing were analysed using logistic regression.

\section{Results}

Between 2000 and 2005, age-adjusted use of recommended beta-blockers rose from $6.1 \%$ to $27.0 \%$ in men, and from $4.2 \%$ to $21.5 \%$ in women. In 2005 , younger patients were more likely to be treated; the fully adjusted odds ratio was 4.83 (95\% confidence interval $=3.78$ to 6.17 ) for patients aged $60-64$ years compared with those aged 85 years. Women and patients living in areas of socioeconomic deprivation were less likely to be treated. In 2005, in addition to treatment with guideline-recommended beta-blockers, a further $11.7 \%$ of men and $12.5 \%$ of women were prescribed other beta-blockers.

\section{Conclusion}

Recommended beta-blocker use has risen in the UK but remains low and inequitable, with many patients still treated with beta-blockers that are not recommended in guidelines. This suggests further improvements in prescribing are still possible.

Keywords

adrenergic; beta-blockers; equity; heart failure.

\section{INTRODUCTION}

Heart failure is a common condition in primary care, leading to high morbidity and mortality. ${ }^{1}$ Randomised controlled trials have confirmed that beta-blocker therapy improves survival and reduces hospitalisation for patients with left ventricular systolic dysfunction. ${ }^{2,3}$ The studies suggest that this is not a class effect, with evidence limited to bisoprolol, carvedilol, metoprolol, and nebivolol. ${ }^{4-6}$ This is reflected in international guidelines, which recommend their initiation, in combination with angiotensin-converting enzyme (ACE) inhibitors, for all patients with heart failure and systolic dysfunction. . $^{4-6}$

Qualitative studies in primary care have found that initiating new heart failure pharmacotherapy is problematic for a number of reasons, including sideeffects, diagnostic uncertainty, and concern over the generalisability of evidence. ${ }^{7-10} \mathrm{~A}$ number of studies in other countries suggest that beta-blocker therapy is underused, with age and sex inequities. ${ }^{11-16}$ Little is known about recent trends and current inequities in the UK; the available evidence suggests low use compared with other European countries, but this predates the inclusion of beta-blocker therapy in national guidelines. ${ }^{17,18}$ In this article a large representative primary care database is used to describe trends and inequities in beta-blocker use since 2000 .

SM Shah, BSc, MSc, MFPH, senior lecturer; IM Carey, BSc, $M S c, P h D$, research fellow; S DeWilde, MRCGP, DRCOG, $M D$, clinical research fellow; DG Cook, BSc, MSc, PhD, professor of epidemiology, Division of Community Health Sciences, St George's, University of London. N Richards, BSc, former director, Cegedim Strategic Data UK Limited, Chertsey, Surrey.

Address for correspondence

Dr Sunil Shah, Senior Lecturer, St George's,

University of London, Cranmer Terrace, SW17 0RE.

E-mail: sushah@sgul.ac.uk

Submitted: 15 February 2008; Editor's response: 10 April 2008; final acceptance: 30 June 2008.

(c) British Journal of General Practice.

This article was originally online first. Cite this article as: Br J Gen Pract 2008; 58: 862-869. Advance online publication. DOI: 10.3399/bjgp08X376195 


\section{METHOD}

\section{DIN-LINK}

DIN-LINK (formerly DIN [Doctors' Independent Network]) is an anonymised computerised UK primary care database from practices that use iSOFT (formerly Torex) software (iSOFT Group plc, Manchester, UK). This report is based on 152 practices with continuous high-quality recording from 2000 to 2005. Methods have been outlined for identifying good-quality data in DIN-LINK and this approach was repeated. ${ }^{19}$ Prevalence rates for a wide range of conditions including coronary heart disease (CHD) and atrial fibrillation (AF) compare well with other national data sources. ${ }^{20,21}$

Morbidity and prescription data are coded by Read codes. An important aspect of the database is the availability of a sociodemographic indicator linked to patient postcode, the ACORN index (CACl Limited) which uses data from the 2001 census to classify small areas into sociodemographic groups..$^{19,22}$ ACORN scores were available for $98 \%$ of patients in 148 of the 152 practices. ACORN data were mainly missing for the other four practices due to technical problems with linkage, unrelated to type of practice.

\section{Subjects}

Patients aged $\geq 50$ years on 31 December of each year were included if they had already been registered with the practice for 6 months. There were an average of 426000 patients aged $\geq 50$ years year included in the study. Patients with heart failure were identified based on the recording of a Read code for heart failure using the definition of heart failure from the 2006 revision of the Quality and Outcomes Framework (QOF). ${ }^{23}$ The QOF is part of the new primary care contract in England, which aims to improve the quality of chronic disease management through financial incentives for achievement of specific clinical targets.

Patients were classified as actively managed if they had received two prescriptions of an ACE inhibitor or angiotensin receptor blocker (ARB) during the calendar year. Patients with actively managed heart failure were identified as the target group for beta-blocker therapy in primary care, that is patients with heart failure due to left ventricular systolic dysfunction.

\section{Beta-blocker prescribing}

Patients were classified as receiving recommended beta-blocker therapy if they received a prescription of bisoprolol, carvedilol, metoprolol, or nebivolol during the calendar year. These drugs were identified as recommended, based on randomised control trial evidence of effectiveness, which is summarised in international guidelines. ${ }^{4-6}$ Metoprolol was included in the definition of recommended beta-blockers but it should be recognised that the evidence base for

\section{How this fits in}

Treatment with specific beta-blockers reduces mortality and hospitalisation in heart failure, but qualitative studies show that primary care physicians find initiating new pharmacotherapy for heart failure difficult. Between 2000 and 2005 , use of recommended beta-blockers rose but primary care prescribing is still low, with evidence of age, sex, and socioeconomic inequity. A sizeable proportion of patients with heart failure are treated with non-recommended betablockers, with limited evidence for their effectiveness. Further improvements in beta-blocker prescribing are possible in the UK, through increased uptake, improved equity of access, and further guidance on the choice of beta-blocker.

immediate-release metoprolol, available in the UK, is now uncertain. ${ }^{24}$ The decision to include it was based on the widespread historical recommendations for its use during the study period. A prescription of any other beta-blocker during the year was classified as 'other beta-blocker therapy'.

\section{Analysis}

The proportion of patients receiving treatment between 2000 and 2005 was directly age standardised to the relevant combined 2005 population for men and women, using 5-year age groups. Ninety-five per cent confidence intervals (Cls) were calculated, taking account of clustering at practice level.

Factors predicting the prescribing of beta-blockers in 2005 were analysed using a hierarchical logistic model with PROC GENMOD in SAS (version 9.1 for Solaris [SAS Institute, Cary, NC]), with practices at level 2 and individual patients at level 1. Factors included in the model were years since initial diagnosis, ischaemic heart disease (IHD) type, asthma or chronic obstructive pulmonary disease (COPD) ever (or both), hypertension ever, AF status, history of echocardiogram request, ACORN group, practice region, and urban/rural status. All explanatory variables were fitted as fixed effects at the patient level, except urban/rural status and region of practice, which were fitted as a fixed effect at practice level. A random effect for practice was fitted to model variation across practices. The comparison group for patients receiving a recommended betablocker and patients receiving other beta-blockers was patients receiving neither.

\section{RESULTS}

\section{Prevalence of heart failure}

In 2005,5075 (2.47\%, $95 \% \mathrm{Cl}=2.30$ to 2.81$)$ men and $5765(2.49 \%, 95 \% \mathrm{Cl}=2.34$ to 2.78$)$ women aged $\geq 50$ years were identified with any heart failure diagnosis recorded ever, irrespective of current management. Between 2000 and 2005, the ageadjusted prevalence of heart failure ever fell from $3.72 \%$ to $2.88 \%$ for men and from $3.03 \%$ to $2.16 \%$ for women (Figure 1). 
Figure 1. Trends in the age-adjusted prevalence of heart failure ever and actively managed heart failure in patients aged $\geq 50$ years.

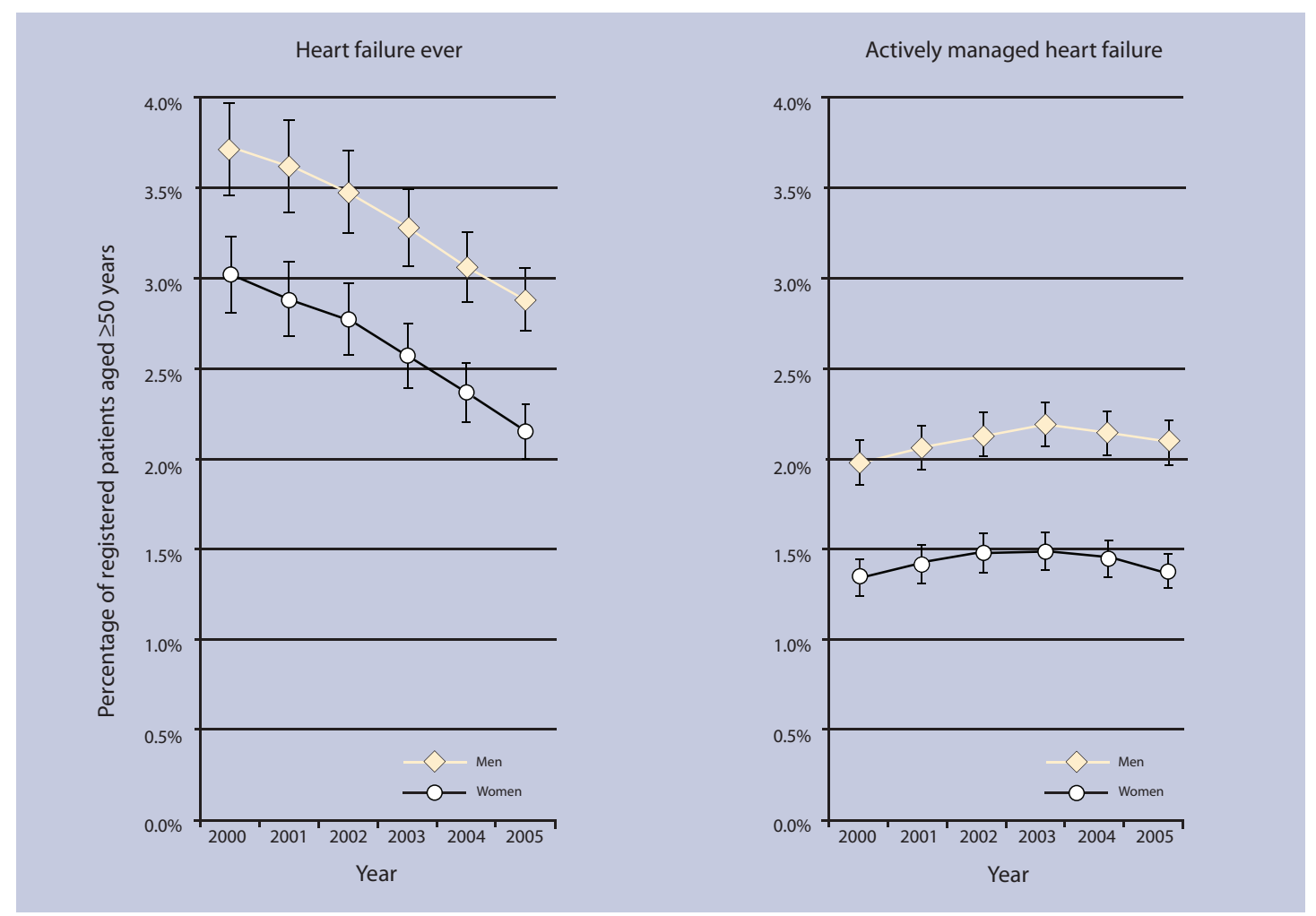

ACE inhibitor prescribing and actively managed heart failure

Patients with heart failure who received two prescriptions of an ACE inhibitor or ARB during the calendar year were identified as having 'actively managed heart failure'. Among patients with any heart failure diagnosis between 2000 and 2005, age-adjusted ACE inhibitor or ARB prescribing rose from $52.5 \%$ to $72.0 \%$ for men, and from $45.2 \%$ to $64.9 \%$ for women. This rise is mainly explained by the decreasing number of patients identified with heart failure rather than a true increase in ACE inhibitor prescribing. Thus, between 2000 and 2005, the age-adjusted prevalence of actively managed heart failure was little changed (Figure 1).

In 2005, 3777 (1.84\%, age adjusted 2.10\%) men and 3638 (1.57\%, age adjusted $1.38 \%)$ women aged $\geq 50$ years were identified with actively managed heart failure. The prevalence of actively managed heart failure rose with age and was higher for men in all age groups.

\section{Beta-blocker prescribing}

In 2005, $1100(29.1 \%, 95 \% \mathrm{Cl}=27.1$ to 31.1$)$ men and $737(20.3 \%, 95 \% \mathrm{Cl}=18.3$ to 22.2$)$ women with actively managed heart failure received a prescription for a recommended beta-blocker. A further 470 $(12.4 \%, 95 \% \mathrm{Cl}=11.3$ to 13.6$)$ men and 438 (12.0\%, $95 \% \mathrm{Cl}=11.0$ to 13.1 ) women were receiving other beta-blockers (Table 1). For both sexes, both recommended and other beta-blocker use was lower in older age groups.

\section{Trend in beta-blocker use}

The age-adjusted use of recommended beta-blockers in those with actively managed heart failure rose sharply between 2000 and 2005 from $6.2 \%(95 \% \mathrm{Cl}=$ 5.2 to 7.3$)$ to $27.0 \%(95 \% \mathrm{Cl}=25.1$ to 28.9$)$ for men, and from $4.2 \%(95 \% \mathrm{Cl}=3.4$ to $5.0 \%)$ to $21.5 \%(95 \%$ $\mathrm{Cl}=19.5$ to 23.5$)$ for women. The use of other betablockers increased from $8.7 \%(95 \% \mathrm{Cl}=7.6$ to 9.8$)$ to $11.7 \%(95 \% \mathrm{Cl}=10.5$ to 12.9$)$ in men, and from $9.8 \%$ $(95 \% \mathrm{Cl}=8.7$ to 10.8$)$ to $12.5 \%(95 \% \mathrm{Cl}=11.4$ to 13.6$)$ in women (Figure 2).

Re-analysis with the exclusion of metoprolol made no difference to the conclusions on either trends or determinants of use. Similarly, the data were reanalysed using a 'two prescriptions in a year' definition of beta-blocker use; it was found that this led to an absolute reduction of approximately $5 \%$ of betablocker use in each year but did not alter the trend.

\section{Choice of beta-blockers}

In 2005, 1292 (70\%) of patients receiving active management and a recommended beta-blocker were treated with bisoprolol. Carvedilolol, metoprolol, and nebivolol accounted for $21 \%, 8 \%$, and $1 \%$ of those patients being treated with a recommended betablocker respectively. The main other beta-blockers prescribed were atenolol (86\%), sotalol (9\%), and propranolol (3\%).

\section{Determinants of beta-blocker prescribing}

In 2005, prescription of a recommended beta-blocker 
Table 1. Number and percentage of patients with actively managed heart failure treated with recommended and other beta-blockers in 2005.

\begin{tabular}{|c|c|c|c|c|c|c|}
\hline \multirow[b]{2}{*}{ Age, years } & \multicolumn{3}{|c|}{ Men } & \multicolumn{3}{|c|}{ Women } \\
\hline & $\begin{array}{c}\text { All actively } \\
\text { managed } \\
\text { patients }\end{array}$ & $\begin{array}{c}\text { Other } \\
\text { beta-blocker } \\
n(\%)\end{array}$ & $\begin{array}{c}\text { Recommended } \\
\text { beta-blocker } \\
n(\%)\end{array}$ & $\begin{array}{l}\text { All actively } \\
\text { managed } \\
\text { patients }\end{array}$ & $\begin{array}{c}\text { Other } \\
\text { beta-blocker } \\
n(\%)\end{array}$ & $\begin{array}{c}\text { Recommended } \\
\text { beta-blocker } \\
n(\%)\end{array}$ \\
\hline $50-54$ & 91 & 12 (13.2) & 35 (38.5) & 29 & $3(10.3)$ & 7 (24.1) \\
\hline $55-59$ & 183 & 34 (18.6) & 85 (46.4) & 66 & $8(12.1)$ & $20(30.3)$ \\
\hline $60-64$ & 296 & 46 (15.5) & $128(43.2)$ & 120 & 14 (11.7) & 38 (31.7) \\
\hline $65-69$ & 408 & $73(17.9)$ & 145 (35.5) & 213 & 35 (16.4) & $58(27.2)$ \\
\hline 70-74 & 632 & 91 (14.4) & $220(34.8)$ & 422 & $62(14.7)$ & $102(24.2)$ \\
\hline 75-79 & 783 & 89 (11.4) & 211 (26.9) & 698 & 98 (14.0) & $159(22.8)$ \\
\hline $80-84$ & 783 & $76(9.7)$ & 179 (22.9) & 906 & 110 (12.1) & 180 (19.9) \\
\hline$\geq 85$ & 601 & $49(8.2)$ & 97 (16.1) & 1184 & $108(9.1)$ & $173(14.6)$ \\
\hline $\begin{array}{l}\text { All, \% } \\
95 \% \mathrm{Cl}\end{array}$ & 3777 & $\begin{array}{c}470(12.4) \\
11.3 \text { to } 13.6\end{array}$ & $\begin{array}{c}1100(29.1) \\
27.1 \text { to } 31.1\end{array}$ & 3638 & $\begin{array}{c}438(12.0) \\
11.0 \text { to } 13.1\end{array}$ & $\begin{array}{c}737(20.3) \\
18.3 \text { to } 22.2\end{array}$ \\
\hline $\begin{array}{l}\text { Adjusted, }{ }^{a} \% \\
95 \% \mathrm{Cl}\end{array}$ & & $\begin{array}{c}11.7 \\
10.5 \text { to } 12.9\end{array}$ & $\begin{array}{c}27.0 \\
25.1 \text { to } 28.9\end{array}$ & & $\begin{array}{c}12.5 \\
11.4 \text { to } 13.6\end{array}$ & $\begin{array}{c}21.5 \\
19.5 \text { to } 23.5\end{array}$ \\
\hline
\end{tabular}

${ }^{\mathrm{a}}$ Age adjusted to combined male and female 2005 population. was less likely among older people, with a patient aged 60-64 years being almost four times more likely to receive treatment than a patient aged $>85$ years, after adjustment for sex and practice effects (odds ratio [OR] $=3.87,95 \% \mathrm{Cl}=3.09$ to 4.84$)$. Women $(\mathrm{OR}=0.73$, $95 \% \mathrm{Cl}=0.65$ to 0.83 , for women compared with men) and patients living in areas of deprivation $(\mathrm{OR}=0.79$, $95 \% \mathrm{Cl}=0.67$ to 0.92 for the most deprived compared with the most affluent) were less likely to receive treatment (Table 2).

A history of COPD or asthma greatly reduced the likelihood of treatment, while a history of IHD, hypertension, or active AF increased the likelihood of treatment (Table 2). Diabetes did not influence the likelihood of treatment (data not shown). Patients with a recorded echocardiography or a recent diagnosis of heart failure were more likely to be treated with a recommended beta-blocker. These differences persisted after full adjustment in a model that included demographic factors and comorbidities, including history of COPD or asthma, IHD, AF, hypertension, history of echocardiography, and time since diagnosis (Table 2). After full adjustment, younger patients, aged 60-64 years, were still much more likely to receive

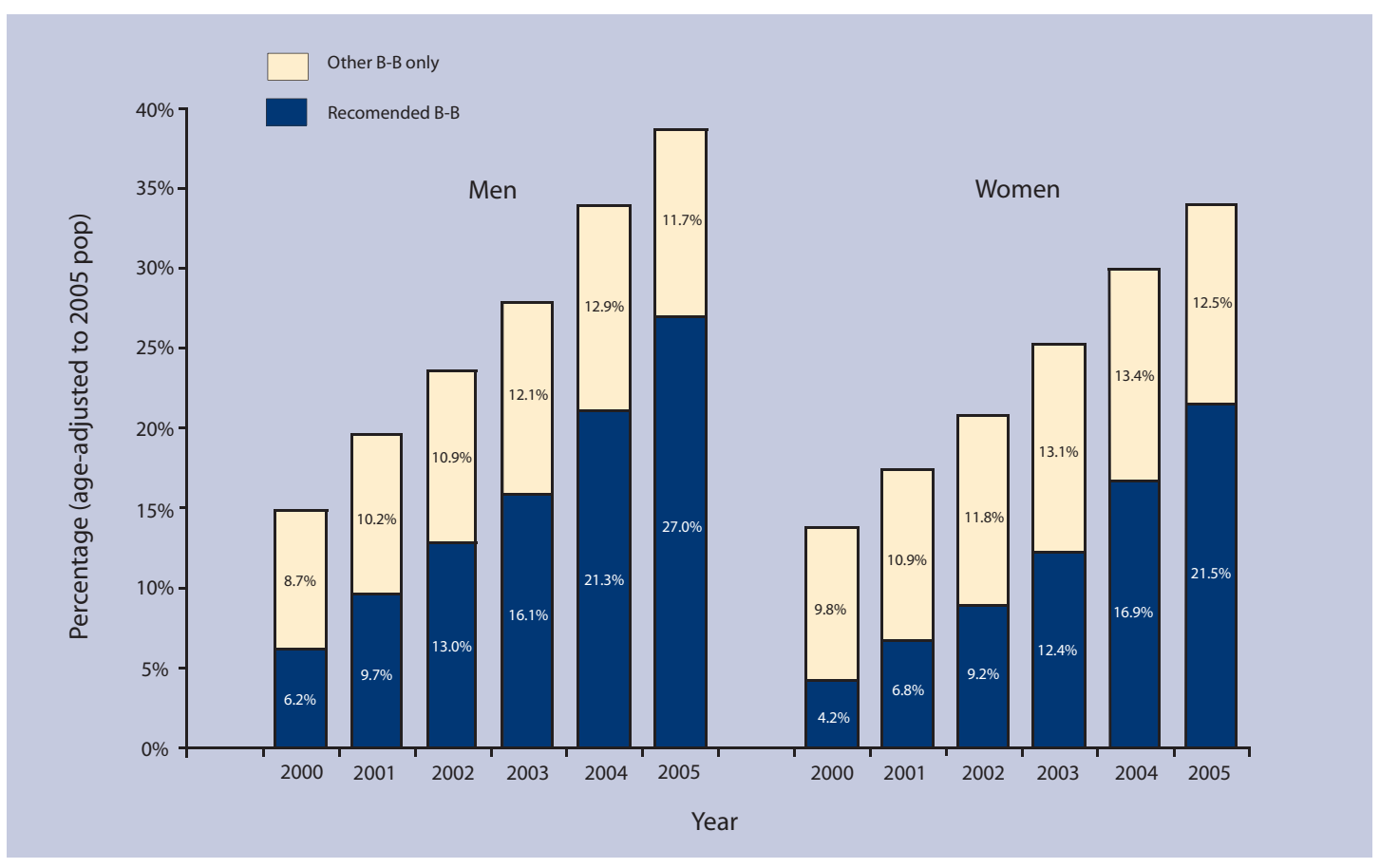

Figure 2. Trend in precentage of patients with actively managed heart failure treated with recommended and other beta-blockers (2000-2005). 
Table 2. Odds ratios for beta-blocker prescribing (recommended and other versus none) in actively managed heart failure in 2005.

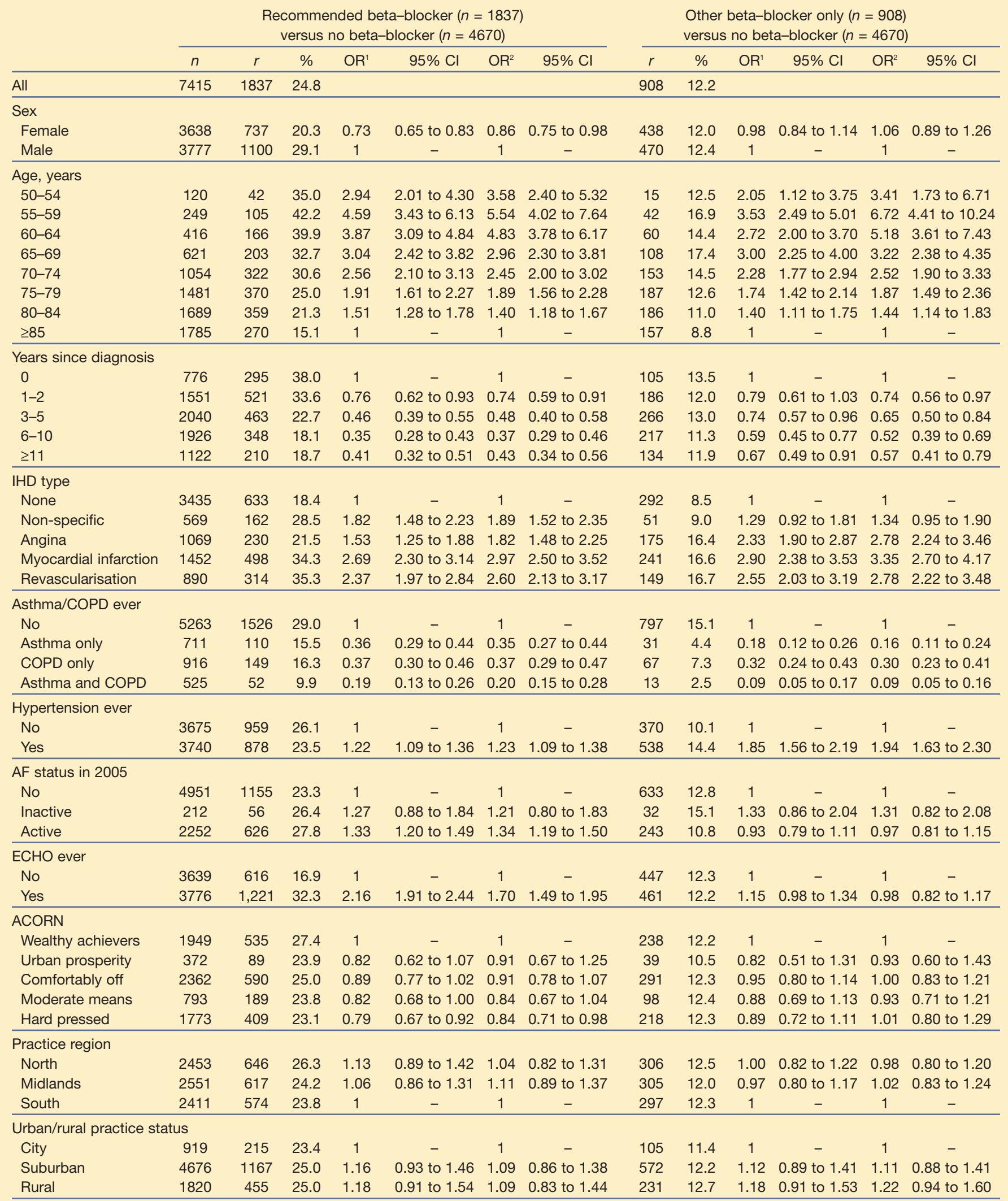

$A F=$ atrial fibriliation. $C O P D=$ chronic obstructive pulmonary disease. $E C H O=$ echocardiography. IHD = ischaemic heart disease. OR ${ }^{1}=$ adjusted for age, sex and practice only. $O R^{2}=$ odds ratio adjusted for all factors. 
treatment than those aged $\geq 85$ years $(O R=4.83,95 \%$ $\mathrm{Cl}=3.78$ to 6.17$)$.

For treatment with other beta-blockers, age and a history of respiratory disease were associated with a lower likelihood of treatment, while a recent diagnosis, history of IHD, and history of hypertension were associated with a greater likelihood of treatment. Other factors, including sex and deprivation, did not influence the likelihood of treatment with other beta-blockers.

\section{DISCUSSION}

\section{Summary of main findings}

It was found that beta-blocker therapy has risen among patients with heart failure, and this is predominantly accounted for by the increased use of beta-blockers with evidence of benefit in heart failure. Nevertheless, many patients are treated with betablockers with limited evidence for their effectiveness and the overall proportion receiving any beta-blocker is suboptimal, with lower treatment levels for older people, women, and patients in areas of deprivation.

\section{Strengths and limitations of the study}

The authors believe this is the first large, nationally representative primary care study to examine betablocker use since the introduction of the new primary care contract and widespread acceptance of the evidence base for beta-blockers. Unlike many previous studies, this one has distinguished between the use of recommended and other beta-blockers.

The study's definition of heart failure relies on accurate identification and coding within primary care. Other authors have suggested that heart failure coding in primary care is relatively complete with $87 \%$ sensitivity compared with drug and hand searching. ${ }^{25}$ The main issue is likely to be the diagnostic certainty of a heart failure diagnosis in primary care and accurate identification of those with left ventricular systolic dysfunction. ${ }^{9,10}$ The falling prevalence of any heart failure suggests that improved access to investigations and a more stringent application of criteria is leading to the revision of diagnoses. This fall may be partly explained by the introduction of the QOF, which provides indirect incentives for a more stringent application of diagnostic criteria. ${ }^{26}$ Limiting the analysis in this study to patients who have been prescribed an ACE inhibitor reduces this effect and is likely to identify those with confirmed or probable left ventricular sysytolic dysfunction. However, it has not been possible to validate this pragmatic approach to identifying patients with left ventricular sysytolic dysfunction, and patients with intolerance to ACE inhibitors will be excluded.

\section{Comparison with existing literature}

A number of studies have examined the use of beta- blockers among patients with heart failure. The majority have studied hospital discharge or outpatient populations or were conducted outside the UK. ${ }^{11-16}$ These studies have generally reported higher utilisation of beta-blockers. The EuroHeart Failure study, a survey of hospital discharges across 24 European countries, reported $36.9 \%$ utilisation in 2000-2001, with a lower proportion in the UK. ${ }^{11}$ Comparable primary carebased UK studies have reported $11.5 \%$ and $10.3 \%$ utilisation for men and women respectively in 1998 in England and Wales, and $23.2 \%$ and $20.0 \%$ for men and women in Scotland in 1999-2000. ${ }^{17,18}$ These are broadly consistent with the present study's overall beta-blocker utilisation of $16.8 \%$ and $13.2 \%$ in 2000 , but do not compare favourably with a Europe-wide primary care utilisation rate of $33 \%$ and $27 \%$ for men and women in 1999-2000. ${ }^{13}$

The study's findings on age inequities are consistent with other studies, irrespective of the population that was investigated. ${ }^{11,13}$ The present study was not able to control for heart failure severity, and a potential partial explanation of the age gradient is poor tolerance of beta-blockers among older people who have more severe disease. Findings on sex inequities are less consistent. Other studies, which have not distinguished between recommended and other betablockers, have reported higher use among men but some have found this difference disappears after adjustment for age. ${ }^{11,13}$ The present findings on the effect of comorbidities on prescribing of beta-blockers are consistent with other studies..$^{11,13}$

\section{Implications for clinical practice and future research}

Trends in beta-blocker use. The rise in recommended beta-blocker use since 2000 suggests that recent evidence is influencing practice. All patients with heart failure will not be suitable for beta-blocker therapy but other studies found that $70-80 \%$ of unselected patients with heart failure are suitable for, and tolerate, beta-blocker therapy. ${ }^{16,27,28}$ Compared with this, the present study's treatment rate with recommended beta-blockers of $24.7 \%$ is low and suggests the potential for further improvements in prescribing. If there is potential for a further $45 \%$ of patients to be treated with recommended beta-blockers, extrapolating the present findings to the whole of the UK, this would suggest up to 155000 additional patients aged over 50 years could be treated. Based on trial evidence, this could, assuming optimal conditions, prevent an additional 7800 deaths and 9750 hospital admissions per year. ${ }^{2}$

Use of non-recommended beta-blockers. The study found that $12 \%$ of patients were prescribed a nonrecommended beta-blocker, primarily atenolol, in 
2005. It cannot be easily determined whether this is new prescribing after the onset of heart failure or a continuation of existing prescribing for other comorbidities. The strong association with history of angina and hypertension suggests that continued prescribing makes an important contribution. Guidelines vary in their position on the continued use of such beta-blockers in heart failure. ${ }^{4-6}$ All are clear that the evidence base is restricted to specific betablockers but the current UK National Institute for Health and Clinical Excellence (NICE) guidelines support continued use of other beta-blockers once heart failure develops. ${ }^{4}$

The NICE guidelines do not fully reflect current evidence as they predate publication of the Carvedilol Or Metoprolol European Trial (COMET), which further questioned the class effect of beta-blockers. ${ }^{24}$ Current guidance on choice of beta-blockers needs updating and it is likely, based on the available evidence, that use of a recommended beta-blocker is preferable..$^{29,30}$

Inequity. Lower recommended beta-blocker utilisation was found among older people, women, and those living in areas of deprivation, independent of any effect of practice on treatment and after adjustment for the key contraindications of COPD and asthma. The strong age gradient in treatment may be partially explained by higher levels of other comorbidity in older patients, but is worrying as there is unequivocal evidence of benefit from beta-blockers for older people who are at highest risk of mortality and hospitalisation. ${ }^{31}$

Further analysis failed to show socioeconomic differences for ACE inhibitor use in heart failure and the authors have also previously failed to find differences for secondary prevention of CHD. ${ }^{32}$ This suggests that patients in areas of deprivation are less likely to receive newer evidence-based treatments but not established therapies. As beta-blocker use is associated with access to secondary or specialist care, this may reflect poorer access to secondary care in deprived areas. ${ }^{33}$ Alternatively, the socioeconomic differences may be explained by residual confounding due to higher levels of morbidity and contraindications in groups from areas of deprivation. However, a lack of socioeconomic differences in prescribing of non-recommended betablockers argues against this explanation.

Policy implications. This study has shown that use of beta-blocker therapy increased between 2000 and 2005 , although it was not included as a specific quality standard in either the original QOF for English primary care in $\mathbf{2 0 0 4}$ or its revision in 2006. Other studies have suggested that the QOF may have improved care for included conditions, even for aspects of care that were not directly incentivised, but may have led to neglect of conditions that were not incentivised. ${ }^{34}$ There is also evidence that improvements in care for heart disease predate introduction of the QOF ${ }^{35}$ The present work is consistent with these findings in that left ventricular sysytolic dysfunction was included in the QOF, although beta-blocker therapy was not a specific requirement, and improvements in beta-blocker prescribing began before 2004. It is not possible to be certain from the present work, but it is plausible that specific inclusion of beta-blocker therapy in the QOF would have further accelerated uptake.

This study suggests that further improvements in beta-blocker prescribing are possible in the UK, through increased uptake, improved equity of access, and further guidance on the choice of beta-blocker.

\section{Funding body}

lain M Carey and Stephen DeWilde were funded by a grant from the BUPA foundation. Stephen DeWilde is also funded by a grant from Cegedim Strategic Data UK Limited

\section{Ethical approval}

This study was approved by the National Heath Service Research Ethics Committee for Wandsworth (05/Q0803/162)

\section{Competing interests}

Nicky Richards was director of Cegedim Strategic Data UK Limited which markets DIN-LINK data to pharmaceutical companies. All other authors have stated that there are none.

\section{Discuss this article}

Contribute and read comments about this article on the Discussion Forum: http://www.rcgp.org.uk/bjgp-discuss

\section{REFERENCES}

1. McMurray JJ, Pfeffer MA. Heart failure. Lancet 2005; 365(9474): 1877-1889.

2. Shibata MC, Flather MD, Wang D. Systematic review of the impact of beta blockers on mortality and hospital admissions in heart failure. Eur J Heart Fail 2001; 3(3): 351-357.

3. Foody JM, Farrell MH, Krumholz HM. Beta-blocker therapy in heart failure: scientific review. JAMA 2002; 287(7): 883-889.

4. National Institute for Clinical Excellence. Chronic heart failure. Management of chronic heart failure in adults in primary and secondary care. London: NICE, 2003

5. The Task Force for the Diagnosis and Treatment of Chronic Heart Failure of the European Society of Cardiology. Guidelines for the diagnosis and treatment of chronic heart failure: executive summary (update 2005). Eur Heart J 2005; 26(11): 1115-1140.

6. Hunt SA, Abraham WT, Chin MH, et al. ACC/AHA 2005 guideline update for the diagnosis and management of chronic heart failure in the adult. Circulation 2005; 112(12): e154-235.

7. Khunti K, Hearnshaw H, Baker R, Grimshaw G. Heart failure in primary care: qualitative study of current management and perceived obstacles to evidence-based diagnosis and management by general practitioners. Eur J Heart Fail 2002; 4(6): 771-777.

8. Hickling JA, Nazareth I, Rogers S. The barriers to effective management of heart failure in general practice. Br J Gen Pract 2001; 51(469): 615-618.

9. Fuat A, Hungin AP, Murphy JJ. Barriers to accurate diagnosis and effective management of heart failure in primary care: qualitative study. BMJ 2003; 326(7382): 196.

10. Phillips SM, Marton RL, Tofler GH. Barriers to diagnosing and managing heart failure in primary care. Med J Aust 2004; 181(2): 78-81.

11. Komajda M, Follath F, Swedberg K, et al. The EuroHeart Failure Survey programme - a survey on the quality of care among patients with heart failure in Europe. Part 2: treatment. Eur Heart J 2003; 24(5): 464-474.

12. Ko DT, Tu JV, Masoudi FA, et al. Quality of care and outcomes of older patients with heart failure hospitalized in the United States and Canada. Arch Intern Med 2005; 165(21): 2486-2492.

13. Muntwyler J, Cohen-Solal A, Freemantle N, et al. Relation of sex, age 
and concomitant diseases to drug prescription for heart failure in primary care in Europe. Eur J Heart Fail 2004; 6(5): 663-668.

14. Smith NL, Chan JD, Rea TD, et al. Time trends in the use of betablockers and other pharmacotherapies in older adults with congestive heart failure. Am Heart J 2004; 148(4): 710-717.

15. Pont LG, Sturkenboom MC, van Gilst WH, et al. Trends in prescribing for heart failure in Dutch primary care from 1996 to 2000. Pharmacoepidemiol Drug Saf 2003; 12(4): 327-334.

16. Watz R, Ekstrand AB, Engelbrektson V, Beermann B. Treatment with angiotensin converting enzyme inhibitors, angiotensin-II-antagonists and beta-blockers in an unselected group of patients with chronic heart failure. Eur J Clin Pharmacol 2005; 61(3): 209-214.

17. Ellis C, Gnani S, Majeed A. The prevalence and management of heart failure in general practice in England and Wales 1994-1998. Health Stat Q 2001; 11: 17-24.

18. McAlister FA, Murphy NF, Simpson CR, et al. Influence of socioeconomic deprivation on the primary care burden and treatment of patients with a diagnosis of heart failure in general practice in Scotland: population based study. BMJ 2004; 328(7448): 1110.

19. Carey IM, Cook DG, De Wilde S, et al. Developing a large electronic primary care database (Doctors' Independent Network) for research. Int J Med Inform 2004; 73(5): 443-453.

20. DeWilde S, Carey IM, Bremner SA, et al. Evolution of statin prescribing 1994-2001: a case of ageism but not of sexism? Heart 2003; 89(4): 417-421.

21. DeWilde S, Carey IM, Emmas C, et al. Trends in the prevalence of diagnosed atrial fibrillation, its treatment with anticoagulation and predictors of such treatment in UK primary care. Heart 2006; 92(8): 1064-1070.

22. CACI Ltd. ACORN user guide. London: CACI Limited, 2001.

23. Department of Health. New GMS contract QOF implementation. Dataset and business rules. Heart failure indicator set. London: Department of Health, 2006.

24. Poole-Wilson PA, Swedberg K, Cleland JG, et al. Comparison of carvedilol and metoprolol on clinical outcomes in patients with chronic heart failure in the Carvedilol Or Metoprolol European Trial (COMET): randomised controlled trial. Lancet 2003; 362(9377): $7-13$.

25. Gnani S, Gray J, Khunti K, Majeed A. Managing heart failure in primary care: first steps in implementing the National Service Framework. J Public Health (Oxf) 2004; 26(1): 42-47.

26. Carey IM, DeWilde S, Harris T, et al. Spurious trends in coronary heart disease incidence: unintended consequence of the new UK GP contract? Br J Gen Pract 2007; 57(539): 486-489.

27. Parameswaran AC, Tang WH, Francis GS, et al. Why do patients fail to receive beta-blockers for chronic heart failure over time? A 'realworld' single-center, 2-year follow-up experience of beta-blocke therapy in patients with chronic heart failure. Am Heart J 2005; 149(5): 921-926.

28. Shelton RJ, Rigby AS, Cleland JG, Clark AL. Effect of a community heart failure clinic on uptake of beta blockers by patients with obstructive airways disease and heart failure. Heart 2006; 92(3): 331-336.

29. Aronson JK. Changing beta-blockers in heart failure: when is a class not a class? Br J Gen Pract 2008; 58(551): 387-389.

30. Mant D, Hobbs FR, Glasziou P, et al. Identification and guided treatment of ventricular dysfunction in a general practice using blood B-type natriuretic peptide. Br J Gen Pract 2008; 58(551): 393-399.

31. Dulin BR, Haas SJ, Abraham WT, Krum H. Do elderly systolic heart failure patients benefit from beta blockers to the same extent as the non-elderly? Meta-analysis of $>12000$ patients in large-scale clinical trials. Am J Cardiol 2005; 95(7): 896-898.

32. DeWilde S, Carey IM, Richards N, et al. Trends in secondary prevention of ischaemic heart disease in the UK 1994-2005: use of individual and combination treatment. Heart 2008; 94(1): 83-88.

33. Rao A, Walsh J. Impact of specialist care in patients with newly diagnosed heart failure: a randomised controlled study. Int J Cardiol 2007; 115(2): 196-202.

34. Steel N, Maisey S, Clark A, et al. Quality of clinical primary care and targeted incentive payments: an observational study. Br J Gen Pract 2007; 57(539): 449-454.

35. Campbell SM, Roland MO, Middleton E, Reeves D. Improvements in quality of clinical care in English general practice 1998-2003: longitudinal observational study. BMJ 2005; 331(7525): 1121. 